\title{
Efficacy of Acute Pain Control Protocol in Triage Department on Analgesics Administration Time and Patients' Satisfaction
}

Seyedhossein Seyyedhoseini Davaraani ${ }^{1}$, Alireza Doroudgar ${ }^{2 *}$, Amir Nejati $^{1}$, Ehsan Sharifipour $^{3}$

1. Imam Khomeini hospital, School of Medicine, Tehran University of Medical Sciences, Tehran, Iran

2. khatamolanbia hospital, School of Medicine, Zahedan university of medical sciences, Zahedan, Iran

3. Department of Neurology, Neurosciences Research Center (NSRC), Student Research committee, School of Medicine, Tabriz University of Medical Sciences, Imam Reza hospital, Tabriz, Iran

\begin{abstract}
Objective: Current study was conducted to develop a pain control protocol by Morphine Sulfate (MS) Suppository in triage ward with the main primary outcomes of first analgesic administration time, patients' satisfaction and also the changes in pain intensity.

Methods: In this randomized clinical trial, 318 consecutive patients attending to an academic tertiary health care center in Tehran, Iran in 2011 and 2012 were enrolled. The patients were randomly assigned to receive either routine pain control by emergency medicine residents in emergency department $(n=132)$ or pain control protocol in triage level by nurses $(n=186)$. Those with pain in control group were treated with conventional pain control program and those in intervention group with pain intensities higher than four were treated with suppository stat $10 \mathrm{mg}$ dose of MS administered by nurses in triage ward.

Results: The mean change in pain intensity was significantly $(P<0.0001)$ higher in intervention group (4.2 versus 0.2 ) and the first analgesic administration time was significantly different between groups $(P<0.05)$ being less in the intervention group (43.1 versus 4.6). Also the patients' satisfaction was significantly higher in the intervention group $(P<0.0001)$. No drug adverse effects were seen.

Conclusions: Totally, according to the obtained results, it may be concluded that acute pain control protocol in triage department by suppository of MS would result in reduced analgesics administration time and higher patients' satisfaction.
\end{abstract}

Keywords: Analgesia; Emergency Department; Pain Control

\section{Corresponding author:}

Alireza Doroudgar, MD

Zahedan University of Medical Sciences, khatamolanbia Hospital, Khatam square, zahedan. Iran

Tel: +989121158705 Email: dr.doroudgar@yahoo.com

Receive date: 2014-04-10 | Accept date: 2014-05-01 | Publish date:

2014-06-29 DOI: 10.7575/aiac.abcmed.14.02.02.13 


\section{Introduction}

Insufficient analgesics prescription (oligoanalgesia) in emergency department has been evaluated in different studies (1-4). Oligoanalgesia has been an important concern in emergency medicine since 1990s (1). The shortness in this field would be more when seeing the pain as the most common symptom among patients attending the emergency departments (5-7). Recent studies demonstrated that pain management guidelines in triage level would result in better pain control in a shorter time $(8,9)$. According to literature, $30-45$ percent of patients attending urban emergency departments require analgesics during admission (1-4). However, the optimal interval from arrival to first analgesic dose prescription should be less than 30 minutes (4). Regarding to importance of pain management in emergency department and high prevalence of pain in patients and prolonged waiting for analgesic administration, different studies have been conducted to develop a guideline for urgent pain control in triage level. However, some studies have shown low efficacy for this method (10).

One of the important challenges is related to lack of a non-injection optimal analgesic that may be administered by the nurse in triage level. Current study was conducted to develop a pain control protocol by MS Suppository in triage ward with main primary outcomes as first analgesic administration time, patients' satisfaction and also the changes in pain intensity.

\section{Methods and materials}

In this randomized clinical trial, 318 consecutive patients attending to an academic tertiary health care center in Tehran, Iran in 2011 and 2012 were enrolled. Patients older than 18 years, with acute pain (initiated form six hours ago), and without analgesic use were enrolled. The exclusion criteria were hemodynamic instability (Triage level ESI 1, 2), abdominal pain, opioid hypersensitivity, and unwillingness to take part in the study. The written informed consent form was signed by all the participants and the Helsinki Declaration was respected all over the study. The study protocol was approved by Ethical Committee of Tehran university of Medical Sciences.

The patients were randomly assigned to receive either routine pain control by emergency medicine residents in emergency department $(n=132)$ or pain control protocol in triage level by nurse $(n=186)$. The pain in arrival was determined and recorded by the nurse in triage ward according to verbal numeric rating scale for both groups and second pain intensity was measured and recorded in emergency department by residents. Those with pain in control group received no treatment until being visited by emergency medicine residents in emergency department and those in intervention group with pain intensities higher than four were treated with suppository stat 10 $\mathrm{mg}$ dose of MS administered by nurses in triage ward. The primary outcomes were first analgesic administration time, patients' satisfaction, and the changes in pain intensity.

Data analysis was performed among 318 subjects including 132 patients in control group and 186 subjects in intervention group using SPSS (version 13.0) software [Statistical Procedures for Social Sciences; Chicago, Illinois, USA]. Independent-sample T, Exact-Fisher, and Chi-Square tests were used for comparison between groups and were considered statistically significant at $P$ values less than 0.05 .

\section{Results}

The mean age of the subjects was 38.71 and 36.23 years in intervention and control groups, respectively $(P>0.05)$. The sex, marital status, 
job, educational level, previous attendance, shift, and cause of analgesic requirement were residence location, addiction history, work alike among the groups $(P>0.05)$ (Table 1$)$.

Table 1: Distribution of demographic and baseline characteristics in two groups

\begin{tabular}{|c|c|c|c|}
\hline \multirow{2}{*}{ Variable } & \multicolumn{2}{|l|}{ Group* } & \multirow{2}{*}{$\begin{array}{c}\mathrm{P} \\
\text { Value }\end{array}$} \\
\hline & Intervention & Control & \\
\hline Male Sex & $61.3 \%$ & $63.6 \%$ & 0.862 \\
\hline Married status & $54.5 \%$ & $80.6 \%$ & 0.083 \\
\hline Academic Educational level & $18.2 \%$ & $12.9 \%$ & 0.936 \\
\hline Job & $54.8 \%$ & $54.5 \%$ & 0.148 \\
\hline Previous attendance & $64.5 \%$ & $72.7 \%$ & 0.528 \\
\hline Capital Residence location & $64.5 \%$ & $54.5 \%$ & 0.679 \\
\hline Addiction history & $9.7 \%$ & $13.6 \%$ & 0.683 \\
\hline Night Work shift & $38.7 \%$ & $59.1 \%$ & 0.274 \\
\hline Multiple Trauma as the cause of analgesic requirement & $16.1 \%$ & $4.5 \%$ & 0.566 \\
\hline
\end{tabular}

The mean change in pain intensity was significantly higher in intervention group (Table 2 ), and the first analgesic administration time was significantly less in the intervention group (43.1 versus 4.6) (Table 2). However the patients' satisfaction was significantly higher in the intervention group (Table 3). No drug adverse effects were seen.

\section{Discussion}

Pain control in emergency department especially in triage level, regardless of attendance cause, is a beneficial attempt to improve patient's outcomes. Since the pain is the most common reason that patients seek care in emergency departments, developing protocols to relieve pain is an issue of importance. This study demonstrated that developing a pain control protocol in triage level prior to emergency department visit by the nurses would result in less waiting time and also better pain management resulting in higher rate of satisfaction from all the services in detail and the total quality of health care services prepared by the emergency department in an academic third-level health care center in a developing country.

We administered the MS suppository as an opioid for nurse-initiated pain control protocol in triage level. In the similar study by Fry et al. morphine was administered as analgesic and the mean pain reduction was 4 . Also, in their study there were 15 adverse events. However, the studied patients in our clinical trial developed no adverse drug effects. The median time to narcotic was 18 minutes that is near to the time found in the current study. The implementation of the results obtained by Fry and colleagues is less than our study due to lack of a control comparison group (11). 
Table 2: Distribution of times and pain intensity scores in two groups

\begin{tabular}{llll}
\hline \multirow{2}{*}{ Variable } & \multicolumn{2}{l}{ Group* } & \multirow{2}{*}{ P Value } \\
\cline { 2 - 3 } & Intervention & Control & \\
\hline First analgesic administration interval (min) & $4.6(1.9)$ & $43.1(12.2)$ & 0.0001 \\
\hline Arrival-analgesic order interval in ED** & $23.48(14.8)$ & $21.36(13.9)$ & 0.633 \\
\hline Order-analgesic administration interval in ED & $18.6(9.5)$ & $19.09(7.8)$ & 0.860 \\
\hline Initial Pain Intensity & $8.13(1.7)$ & $7.41(1.6)$ & 0.129 \\
\hline Final Pain Intensity & $3.9(1.4)$ & $7.68(1.7)$ & 0.0001 \\
\hline Pain Intensity Change & $-4.23(1.7)$ & $0.2(1.3)$ & 0.0001 \\
\hline
\end{tabular}

* Data are presented as mean ( \pm Standard Deviation); ** ED= Emergency Department

Table 3: Distribution of patients' satisfaction in two groups

\begin{tabular}{llll}
\hline \multirow{2}{*}{ Satisfaction from } & \multicolumn{2}{l}{ Group* } & \multirow{2}{*}{ P Value } \\
\cline { 2 - 3 } & Intervention & Control & \\
\hline Analgesia & $96.8 \%$ & $13.6 \%$ & 0.0001 \\
\hline Kindly helps by nurses & $100 \%$ & $36.4 \%$ & 0.0001 \\
\hline Analgesia by nurse & $96.8 \%$ & $13.6 \%$ & 0.0001 \\
\hline Waiting time & $93.5 \%$ & $31.8 \%$ & 0.0001 \\
\hline Totally & $100 \%$ & $36.3 \%$ & 0.0001 \\
\hline
\end{tabular}

The barriers that prohibit emergency physicians from appropriate pain management include ethnic and racial bias, gender bias, age bias, inadequate knowledge and formal training in acute pain management, and fear of opioids use $(12,13)$. The study by Kelly et al.(14) demonstrated a significant and sustained change in analgesia administration practices away from the intramuscular route in favor of the intravenous route. In contrast, intravenous opioids are used more frequently and the proper efficacy seen following MS suppository in our study may be a promising step for further administration of opioids in pain management protocols at triage level by nurses.

The study by Campbell et al. similarly showed that implementation of a pain control protocol for pain management at triage at a busy Level I trauma center, similar to our academic center, would be beneficial to improve patients' outcomes (15). Another study by Fosnocht et al. (16) demonstrated that the use of a triage pain protocol would increase the number of patients who receive analgesics in the emergency department and also use of the protocol results in a decrease in the time to analgesic medication administration that is in 
congruence with our findings in the current study. Similar findings were reported by Seguin for extremity injuries (17). The Study by Finn et al. (18), similar to our study, showed that patients who receive the triage level pain protocol would have statistically significant reduced time to analgesia. Also, Muntlin and colleagues reported that nursing assessment and the nurse-initiated intravenous opioid analgesic would result in significant improvement in frequency of receiving analgesic and a reduction in time to analgesic and also the patients perceive lower pain intensity and improved quality of care in pain management (19). similar to our findings. Therefore, the role of nurses in emergency departments especially in triage levels should not be restricted to pain assessment and the pain management should be incorporated in their work schedule (20).

Totally, according to the obtained results, it may be concluded that acute pain control protocol in triage department, using MS suppository prepared by nurses, would result in reduced analgesics administration time and higher patients' satisfaction. However, further studies should be carried out to ascertain the effectiveness of this method for pain control in emergency departments and also long-term outcomes.

\section{References}

1. Wilson JE, Pendleton JM. Oligoanalgesia in the emergency depart- ment. Am J Emerg Med 1989;7:620-3.

2. Petrack EM, Christopher NC, Kriwinsky J. Pain management in the emergency department: patterns of analgesic utilization. Pediatrics 1997;99:711 - 4.

3. Selbst SM, Clark M. Analgesic use in the emergency department. Ann Emerg Med 1990;19:1010 - 3.

4. Fosnocht DE, Swanson ER, Bossart P. Patient expectations for pain medication delivery. Am J Emerg Med 2001;19:399-402.

5. Barletta JF, Erstad BL, Loew M, Keim SM. A prospective study of pain control in the emergency department. Am J Ther. 2000;7: 251-5.

6. Ducharme J. Proceedings from the First International Symposium on Pain Research in Emergency Departments. Ann Emerg Med. 1996;27:399-403.

7. Gilutz H, Battler A, Rabinowitz I, Snir Y, Porath A, Rabinowitz G. The bdoor-to-needle blitzQ in acute myocardial infarction: the impact of a CQI project. Jt Comm J Qual Improv 1998;24:323-33.

8. Sharieff GQ, Hoecker C, Silva PD. Effects of a pediatric emergency department febrile infant protocol on time to antibiotic therapy. J Emerg Med 2001;21:1-6.

9. Liebelt E, Levick N. Acute pain management, analgesia and anxiolysis in the adult patient. In: Emergency medicine. A com- prehensive study guide. 5th ed. New York: McGraw-Hill; 1999.

10. Goodacre SW, Roden RK. A protocol to improve analgesia use in the accident and emergency department. J Accid Emerg Med 1996;13:177 - 9.

11. Fry $M$, Holdgate A. Nurse-initiated intravenous morphine in the emergency department: efficacy, rate of adverse events and impact on time to analgesia. Emerg Med (Fremantle) 2002;14:249-54

12. Motov SM, Khan AN. Problems and barriers of pain management in the emergency department: Are we ever going to get better? J Pain Res. 2008; 2:5-11. 
13. Rupp T, Delaney KA. Inadequate analgesia in emergency medicine. Ann Emerg Med. 2004; 43:494-503.

14. Kelly AM. Nurse-managed analgesia for renal colic pain in the emergency department. Aust Health Rev 2000;23:185-9.

15. Campbell P, Dennie M, Dougherty K, Iwaskiw O, Rollo K. Implementation of an ED protocol for pain management at triage at a busy Level I trauma center. J Emerg Nurs. 2004; 30:431-8.

16. Fosnocht DE, Swanson ER. Use of a triage pain protocol in the ED. Am J Emerg Med. 2007; 25:791-3.

17. Seguin D. A nurse-initiated pain management advanced triage protocol for ED patients with an extremity injury at a level I trauma center. J Emerg Nurs. 2004; 30:330-5.

18. Finn JC, Rae A, Gibson N, Swift R, Watters T, Jacobs IG. Reducing time to analgesia in the emergency department using a nurse-initiated pain protocol: a before-and-after study. Contemp Nurse. 2012 Aug 18. [In Press]

19. Muntlin A, Carlsson M, Säfwenberg U, Gunningberg L. Outcomes of a nurse-initiated intravenous analgesic protocol for abdominal pain in an emergency department: A quasi-experimental study. Int J Nurs Stud. 2011; 48:13-23.

20. Bible D. Pain assessment at nurse triage: a literature review. Emerg Nurse. 2006; 14:26-9. 